\title{
LA GUERRILLA EN AMÉRICA LATINA ¿TERRORISMO O GUERRA POPULAR?
}

\author{
Judith Larson
}

$\mathrm{El}$ objetivo de este escrito es señalar que las manifestaciones de violencia política en América Latina no son exprestones de terrorismo o de extremismo político, sino una forma embrionaria de lucha armada. El origen de esta lucha armada es la situación neocolonial que caracteriza al continente, en la que el poder imperial (los Estados Unidos, a través de los grupos locales con los que está aliado, básicamente alta burguesía y ejércitos) está dispuesto a impedir con las armas cualquier intento independentista. Los grupos políticos antiimperialistas se encuenttan, por lo tanto, en una situación que les imposibilita aspirar a llegar al poder sin un ejército de liberación que los apoye, provenga él de grupos guerrilletos o de sectores de los ejércitos regulares. Esto les impide actuar dentro de los marcos tradicionales de cualquier partido político occidental, acercándolos más a los movimientos de liberación de Africa o Asia. Es por eso que el uso de categorías políticas adecuadas para la descripción de los fenómenos de violencia en Europa, no lo son para entender la guerrilla latinoamericana, a la que ya no es posible ignorar o reducir a un problema matginal. 


\section{El problema}

La violencia política no es un fenómeno social nuevo: tiene tanta antigüedad como la historia. Sus manifestaciones, en cambio, han variado en diversos períodos históricos y en distintas sociedades. El término mismo engloba una amplia gama de procesos (guerra, revoluciones, insurgencia, terrorismo, contrarrevoluciones, etc.), que tienen, sin embargo, un denominador común: el empleo de las armas para obtener objetivos políticos.

América Latina no ha estado al margen de esta situación que ha aparecido reiteradamente a través de su historia. Los países latinoamericanos consiguieron su independencia política, que les permitió convertirse en estados modernos, por medio de la guerra. $Y$, desde entonces, con mayor o menot intensidad, la violencia ha estado siempre presente en su escena política.

En el tiempo transcurrido desde el fin de la Segunda Guerra Mundial, se han producido, sin embargo, cambios importantes en esta situación. Las explosiones atómicas iniciaron la posibilidad de un desarrollo tal de la tecnología militar, que la humanidad arriesga su supervivencia en un hipotético conflicto armado generalizado. En este contexto, el impedir nuevas guerras mundiales se ha convertido en un imperativo para las grandes potencias. En consecuencia, se han establecido nuevas instancias para resolver conflictos internacionales. La paz se ha transformado en un valor fundamental, simbolizado, por ejemplo, en las Naciones Unidas y en el principio de coexistencia pacífica.

Esta concepción internacional se ha reflejado también a nivel nacional. Es así como, en muchos países occidentales, grupos políticos que sostenían la necesidad de introducir cambios fundamentales y revolucionatios, comenzaron a plantearse la posibilidad de lograrlos a través de los mecanismos democráticos existentes. Surge entonces la proposición de la «vía pacífica al socialismo».

Esta nueva aspiración no es producto solamente del cansancio pro- 
ducido por dos guerras mundiales en los países europeos y el consiguiente anhelo de paz, sino también de una situación social determinada. El desarrollo económico y sus consecuencias en los ámbitos político y cultural, han genetado una situación estructural diferente que ha permitido mayor democratización del sistema político. Es en este contexto que se sostiene que es posible realizar tal programa de cambios sin violencia política. Esto no impide, por cierto, que aun en estas circunstancias aparezcan grupos que propugnen y apliquen la violencia. Pero, si la violencia es innecesaria, aquellos que la proponen pueden ser considerados como extremistas, en la medida en que propugnan soluciones extremas para situaciones que no las requieren.

De modo general, podráamos afirmar que en cualquier lugar del mundo, la mayoría de los grupos políticos que buscan resolver conflictos u obtener objetivos políticos, preferirán hacerlo de modo pacífico. El enorme costo social y económico que significa la violencia es algo que pocas poblaciones se pueden permitir ignorar. ${ }^{2}$ Sin embargo, en América Latina, en el transcurso de los últimos años, la violencia ha crecido y se ha generalizado. ¿Es que ha aumentado la cantidad de «extremistas» latinoamericanos? Ésta parece ser la interpretación más frecuente de la mayoría de la prensa sobre los movimientos guerrilleros de la región. ${ }^{3}$ Sobre todo, en el caso de los países del cono sur (Argentina, Chile, Uruguay), que siempre fueron considerados como los «más europeos» de América del Sur.

Pero no es fácil colocar acertadamente el apelativo de «extremismo» para caracterizar a cualquier grupo político que tecurre a las armas. Si bien hay sociedades en que la violencia política no parece necesaria por la existencia de otros mecanismos alternativos, hay otras en que sigue siendo un elemento importante. Nadie, seguramente, calificaría al Vietcong de «extremista», ni le hubiera aconsejado a Vietnam del Norte hacerle frente a

1. Tal es la posición, por ejemplo, de los partidos comunistas occidentales. No es nuestra intención entrar a analizaria en detalle, pero supone que lo que sucedió en Chile, donde se propugnó igual vía, no sucederá en Europa debico a su nivel de desarrollo económico y de democratización política.

2. El uso continuado de expresiones tales como «terrotista», «subversivo», etc., para calificar cualquier grupo atmado de cualquier parte del mundo ha creado la imagen de que todo guertilleto es un psicópata. Lo cual Hevaría a pensar que todos los palestinos o los iriandeses, por ejemplo, son «intrínsecamente perversos y violentos». La verdad es que son pocas las personas normales que sienten un deseo desenfrenado de sangre y violencia a nivel personal. $Y$ no se encuentran todas en los grupos guerrilleros.

3. Si lo fuera sólo de la prensa que tiene interés en crear esta imagen sería comprensible. Pero también aparece en muchas de las publicaciones progresistas. 
la agresión norteamericana sin el uso de las atmas. Nadie pensaría que las guerras de independencia de los países coloniales fueron obra de grupos de extremistas. Pocos europeos pensarían que al nazismo se le pudo haber combatido de otro modo.

Tenemos aquí, por lo menos, una situación en que hay conflictos y estructuras sociales tales, que es fácil predecir en ella la aparición de la violencia: las situaciones coloniales o neocoloniates (agresión externa). Sería difícil suponer la realización de cambios en ellas, sin la existencia, en alguna medida, de la lucha armada. En este caso, no hay canales de participación política para producir cambios, ni hay posibilidad de verdadera autonomía del país. Primero hay que librarse de la potencia extranjera dominante. Es así como a través de la historia se han producido las llamadas «guerras de independencia nacional».

América Latina vivió sus guerras de independencia colonial de España durante el siglo xIx y principios del Xx. Parecería, pues, que la época de las luchas armadas ya no sería necesaria y que esas sociedades deberían estar en el camino de la construcción de sus países, haciendo uso de las enormes potencialidades de sus recursos. Si bien la imagen que se tiene en el extranjero teconoce en algunos países (por ejemplo, los de Centro América) síntomas de «atraso cultural», otros, caracterizados por una mayo. ría de población de origen europeo y por tasgos culturales altamente desarrollados (por ejemplo, Argentina, Uruguay y Chile) parecen ser ejemplos de países modernos.

Sin embargo, en todos ellos se han desarrollado en los últimos años innumerables grupos guerrilleros y manifestaciones de violencia. Para poder comprender este fenómeno, es necesario romper el mito de la «independencia» de los países latinoamericanos. Si se anatizan con detenimiento las características de la estructura económica de estos países, su debilidad, su dependencia de los Estados Unidos y las características de los grupos políticos dominantes (tanto civiles como militares), nos encontramos con una situación que podríamos caracterizar de neocolonialismo.

El objetivo de este trabajo es mostrar cómo la guetrilla latinoamericana es producto de esta situación neocolonial. Para ello, comenzaremos por describir algunos rasgos de esta situación mostrando, principalmente, cómo los Estados Unidos, el poder imperial, conceptualiza de este modo su relación con América Latina, y cómo ha montado un complejo político, económico y militar para perpetuarla.

Los grupos políticos latinoamericanos verdaderamente interesados en un desarrollo independiente se encuentran así en una situación de mucha debilidad. Es casi imposible el que puedan Ilegar al poder, o puedan mantenerse en él (como fue el caso chileno) sin contat con un ejército de libe- 
ración que los apoye, provenga él de los grupos guerrilleros o de sectores de los ejércitos regulares. No les es posible, por lo tanto, actuar como un partido político de cualquier país europeo (con los cuales se tiende tan a menudo, equivocadamente, a compararlos).

En este contexto, analizatemos si los intentos guerrilleros en su conjunto pueden calificarse de "extremistas» o de «terroristas», o si pueden entmarcarse dentro de lo que se conoce como iniciadores de «movimientos de liberación nacional».

Para diferenciar estos tipos de manifestaciones de la violencia política, es importante distinguir la situación en que ésta aparece, la telación con la población y las formas a través de las cuałes se manifiesta. Si bien éste es un esquema muy simple (un análisis conceptual tnás exhaustivo daría para un trabajo en sí mismo) nos permititá una primera aproximación al tema.

En cuanto a la situación en que aparecen las manifestaciones de violencia, ésta puede estar caracterizada por la existencia de mecanismos de participación política, o por la ausencia de ellos. Al mismo tiempo, por la existencia de grupos extranjeros, considerados como agresores en la medida en que intervienen en la vida nacional, o por la ausencia de ellos. Distinguiremos así la violencia legítima (ausencia de mecanismos de participación $\mathrm{y} / \mathrm{O}$ agresión externa) de la violencia no legítima. ( $\mathrm{El}$ concepto de legitimidad en este caso es un concepto sociológico, no moral.)

La relación con la población, es decir, el apoyo que los grupos que usan la violencia reciben, depende de la variable anterior. Cuanto más legítima sea la violencia recibirá mayor apoyo de la población. Este apoyo varía con el tiempo y el desarrollo de la lucha, peto en el caso de violencia legítima tenderá a crecer en lugar de disminuir. Si bien el poder establecido intentará impedir este crecimiento desvirtuando los objetivos de los grupos tebeldes, en la medida en que estos objetivos son justos, logran, finatmente, el apoyo de la población interesada. Este apoyo puede ser militar o sólo simpatizante, pero en ambos casos hacen que el grupo rebelde crezca en la cantidad de sus miembros y en el consenso sobre su lucha.

Finalmente, podemos distinguir dos tipos de formas de expresión de la violencia: discriminada e indiscriminada. Entendemos por expresión discriminada aquelia que se realiza dentro de un contexto de objetivos político-militares y que afecta a los grupos políticos agresores o usurpadores del poder. La violencia indiscriminada afecta a personas o grupos que no están directamente relacionados con ninguna de las dos situaciones antetiores. En términos de estas tres variables podemos distinguir el extremismo y el terrorismo de los movimientos de liberación nacional.

El extremismo y el tertorismo son fenómenos de violencia política 
que afectan en forma marginal a una sociedad. Practicados por gmapos minoritarios de la población, no encuentran, normalmente, apoyo y tienden a desaparecer con el tiempo, en la medida en que el sistema político permite la libre participación de todos los grupos, en igualdad de condiciones.

Los movimientos de liberación nacional, en cambio, están caracterizados por la combinación de lucha politica y lucha armada (en este sentido violenta) realizadas por grupos nacionales que aspiran a lograr la independencia de su país. Esta forma de lucha ha caracterizado las guerras de los países coloniales por su independencia. Su forma de expresión más usual ha sido la de guerra de guerriłlas, forma habitualmente usada por grupos político-militares, que han debido enf́rentar enemigos con gran superioridad militar. (El término mismo, guerrilla, por ejemplo, aparece en España cuando los españoles luchan contra la invasión napoleónica y en contra de «su rey, Pepe Botella».)

La distinción entre terrorismo y extremismo y la guerra popular (aunque ésta sea en su fase inicial) es uno de los elementos que los grupos que tienen el poder en una situación colonial tratan de obviar, calificando de terrorista a cualquier grupo que emprende la lucha armada. Sin enbargo, como hemos señalado, un estudio objetivo del accionar de los grupos guerrilleros, permite establecer las diferencias entre los distintos tipos de manifestación de la violencia. En ese sentido se tratará de identificar las características fundamentales de cada uno de los tipos de violencia en América Latina.

\section{El escenario}

A partir de la revolución cubana, innumerables focos guerrilleros hacen su aparición en Latinoamérica. Surgen en los países en que el fenómeno de la violencia está más arraigado (algunos países centroamericanos, Colombia y Bolivia, por ejemplo). Países caracterizados por dictaduras militares, inestabilidad política y sus invariables secuencias. Son los países más «subdesarrollados» $\mathrm{y}$ «tradicionales» en términos de la ideología social imperante. Para muchos, esta nueva forma de violencia política no pasa de ser una nueva manifestación de la inestabilidad crónica.

Frente a ellos, en cambio, se destacan como alternativa los países «modernos», aquellos con «mayor proporción de clase media», que "cuentan con mayor posibilidad de reclutar una élite de empresarios innovado res», «más urbanos», «más industrializados», etc., en los que la violencia guertillera parecía imposible. La guerrilla parecía un fenómeno exclusivo de los países «atrasados», condenados a desaparecer. Hoy, ya casi nadie 
se atrevería a afirmar lo mismo. Pues sucede que los paises «más europeos» (Argentina, Chile y Uruguay) se han «latinoameticanizado».

Lo cual es explicable. La década del sesenta sirvió para clarificar tanto teórica como prácticamente los mitos de las teorías de «desarrollo» y "modernización». La reconceptualización de la situación de los países latinoamericanos, en términos de su posición de independencia, permite comprender cuál es la raíz de los problemas a los que se debe hacer frente ¿Qué señala este nuevo enfoque? Que el origen de la situación de atraso no se encuentra en las características culturales, sino en la dependencia económica con respecto al centro capitalista internacional. En este caso, con respecto a los monopolios norteamericanos y a los Estados Unidos mismos, en la medida en que su gobierno protege sus inteteses.

La noción de dependencia señala que la situación de América Latina puede ser caracterizada como un caso de neocolonialismo en el que existe independencia política formal (dentro de ciertos límites) y dependencia económica casi absoluta. Las corporaciones multinacionales controlan los sectores más importantes de la economía al ser propietarias de los recursos principales y de los sectores industriaies más desarrollados. Esto les permite intervenir políticamente, ya sea directa o indirectamente, para proteger sus intereses y mantener el statu quo. A diferencia de un país colonial, los países latinoamericanos tienen sus propias instituciones, sus ptopios ejércitos y su propio gobierno. Sin embargo, la debilidad económica de sus burguesías y grupos políticos dominantes, los convierten en constantes aliados de la política y de los intereses de las multinacionales. Este nuevo imperialismo no administra directamente los países que domina (como el colonialismo), pero fija los límites de las reglas del juego. Sólo se encarga de establecer los planes generales, dejando la realización de los proyectos y la ejecución de los mismos a sus aliados locales, a quienes financia o con quienes establece intereses comunes.

Escapa a los límites de este trabajo la descripción de los mecanismos del neocolonialismo. Sólo nos interesa destacar que se convierte en uno de los elementos más importantes para entender los procesos políticos (marcado, por supuesto, por las propias características de la formación social de cada país) de América Latina. Si bien los aspectos económicos y políticos de la dependencia han sido objeto de gran cantidad de estudios, sólo recientemente se ha comenzado el trabajo de sistematización de información sobre los aspectos militares. Señalaremos brevemente algunos datos, pues creemos que tienen una importante relación con el desarrollo de la lucha armada.

La política imperialista de los Estados Unidos no es nueva ni es característica de sólo algunos grupos norteamericanos. Su política inter- 
nacional se ha caracterizado desde el siglo xrx por la necesidad de la expansión cometcial como modo de resolver sus problemas internos. ${ }^{4}$ Los motivos inmediatos para la expansión y los mecanismos de control de la misma han variado con el tiempo. Hoy los Estados Unidos buscan mantener y prolongar su situación hegemónica en los países del Tercer Mundo que domina. Ella le permite el libre acceso a sus mercados para vender sus productos y dar salida a sus capitales sobrantes y para obtener materias primas y mano de obra barata. Es a causa de esta necesidad de mantener la begemonía en el Tercer Mundo por lo que el aparato militar americano fue sustancialmente modificado en los sesenta por el presidente Kennedy.

Desde el fin de la Segunda Guerra Mundial, la política militar de los Estados Unidos se había centrado en el posible enfrentamiento con la Unión Soviética en una guerra de tipo nuclear. La tecnología y las estrategias de guerra desartolladas fueron condicionadas a tal eventualidad. Las intervenciones en los países del Tetcer Mundo no tienen prioridad militar. Sin embargo, el crecimiento de los tnovimientos de liberación nacional en momentos en que las inversiones en estos países crecían en importancia, y especialmente su éxito en Dien Bien Fu (1954), Cuba (1959) y Argelia (1962) obligan al gobierno norteamericano a llevar a cabo una total revisión de su estrategia militar. Ya hacia fines de los cincuenta, el general Maxwell D. Taylor había comenzado a cuestionar la otientación del Pentágono, apoyado por un pequeño peto influyente grupo de cientifistas políticos y profesores académicos (entre los que se contaba Henry A. Kissinger). Sin embargo, no es hasta que Kennedy se convierte en presidente de los Estados Unidos que la nueva doctrina se convierte en la política militar del gobierno. El establishment militar es reorganizado por Robext

4. Kiate señala que: «De las casi 160 ocasiones en que las fuerzas armadas notteamericanas se emplearon en territorios extranjeros entre 1798 y 1945 , una mayoría abrumadora de veces se trató de la ocupación de un pais del Tercer Mundo. Por ejemplo, de 1900 a 1925 , las tropas norteamericanas fueron enviadas "para proteger intereses norteamericanos" "para restablecer el orden" durante "períodos de actividad revolucionatia"; a China (siete veces), Colombia (tres veces), Cuba (tres veces), República Dominicana (cuatro veces), Guatemala (dos veces), Haiti (dos veces), Honduras (siete veces), Corea (dos veces), México (tres veces), Marruecos, Nicaragua (dos veces), Panamá (seis veces), Filipinas, Siria y Tuxquía (dos veces). Entre las intervenciones de más larga duración figuran la de Haití, república ocupada por las fuerzas norteamericanas desde 1915 hasta 1934 , "a fin de mantener el orden durante un período de crónica y amenazadora insurrección", e intervención en Cuba de 1917 a 1933, "para proteger los intereses norteamericanos durante una insurrección y las subsiguientes circunstancias de inestabilidad"." Michael T. Klate, La guerra sin fin (Barcelona: Noguer, 1974), p. 35. 
S. Mac Namara, un joven ejecutivo proveniente de la Ford Motor Company (simbólica alianza). La transformación que sufrió el Ministerio de Defensa y todo el aparato militar notteamericano se ba mantenido (con cambios de forma) prácticamente igual hasta nuestros días y, probablemente, perdurará por un largo tiempo aún. Su tesis principal: la del desarrollo de una fuerza de contrainsurgencia capaz de intervenir rápidamente y con toda eficacia en cualquier área en que los intereses norteamericanos estuvieran en peligto. Corno señala Klare: «Esta exposición queda confirmada en un fascinante informe que preparó la Douglas Aircraft Company por encargo de la Oficina de Investigación del Ejército, en 1965. En su origen el informe en cuestión se titulaba "Pax Americana", pero luego, cuando el Comité de Relaciones Exteriores del Senado mostró interés por el documento, éste recibió un nuevo título: Disposiciones estratégicas y objetivos militares (Strategic Alignments and Military Objectives). Pese a que el informe en cuestión mereció ser clasificado como "secreto" en los ámbitos militares, el senador Karl E. Mundt consiguió tener un ejemplar en sus manos y más tarde proporcionó a la Comisión de Asuntos Exteriores del Senado los siguientes extractos de las conclusiones generales del informe: "Si bien es cierto que los Estados Unidos no constituyen una nación im" perialista, tampoco cabe negar que en ellos concurren muchos rasgos propios de los imperios del pasado, y que, de hecho, han contraido tesponsabilidades imperiales.

»"El ejército será el principal instrumento militar para la continuación de las funciones directivas de los Estados Unidos en el extranjero y en el interior.

»"Probablemente, Ia función principal del Ejército en el futuro consis. tirá en robustecer las naciones (es decir, pacificarlas y mantener el orden en ellas) y en vigilar las fronteras del imperium de los Estados Unidos. A este respecto, debemos referimos, aquí, a la pasada y presente función del Ejército en Filipinas, Taiwan, Europa, Corea del Sur, Tailandia y, ahora, Vietnam del Sur"., 5

Los principios fundamentales de la doctrina de contrainsurgencia son cuatro: rápido despliegue, tecnología electrónica, organización mercenaria y uso de las ciencias sociales.

El principio del rápido despliegue señala que las fuerzas militares norteamericanas deben estar listas para intervenir en cualquier lugar del mundo que lo requiera, con gran rapidez. La tecnología electrónica consiste en el empleo de los procesos tecnológicos más sofisticados para localizar y

5. Ibid..., pp. 36-37. 
destruir a los grupos enemigos. Éstos incluyen desartollo de bombas especiales, productos químicos, satélites «espías» y, sobre todo, las «técnicas de tortura», tanto físicas como psicológicas, cuyas aplicaciones en Chile, Atgentina y otros países han sido condenadas repetidamente. El desarrollo de fuerzas mercenarias implica la preferencia por el empleo de grupos locales cuando esto sea posible (ya sean grupos civiles, militares o paramilitares). La guerra de Vietnam, con los consecuentes problemas de resistencia interna en los Estados Unidos a la intervención, han puesto esta necesidad como una de las prioritarias actualmente. La organización mercenaria descansa en el financiamiento que se le da a grupos internos aliados para ocupar puestos políticos $o$, cuando se trata de ejércitos, para tomar el poder. En el caso de los ejércitos, éstos son entrenados tanto para tareas policiales como para tareas políticas (la escuela de Panamá es uno de los lugares que proporciona este entrenamiento). La supervisión en el terreno está a cargo de los «consejeros militares» norteamericanos. Finalmente, las ciencias sociales han proporcionado herramientas técnicas para obtener y elaborar la información sobre la realidad política, económica y social que puede ser de ayuda para el montaje contrainsurgente (ubicar grupos potencialmente aliados y lideres opuestos a los Estados Unidos, entre otros datos).

Estos principios de contrainsurgencia, a pesar del fracaso de Vietnam, siguen rigiendo la política de los Estados Unidos en materia de defensa. ${ }^{6}$ Ellos han orientado también la política con respecto a América Latina, marcada por el temor a que se repita la experiencia cubana en otros países.

Durante los años que siguieron a la Segunda Guerra Mundial, los Estados Unidos firmaron pactos de ayuda mutua con la mayoría de los países latinoamericanos, proveyendo de armas de guerta modetnas para la defensa en caso de agresiones externas. Estos programas militares se realizan a través del Programa de Ayuda Militar (Military Assistance Program, MAP). A partir de 1963, según la nueva orientación militar norteamericana, el programa del MAP se dedica fundamentalmente al entrenamiento de los ejércitos latinoamericanos en contrainsurgencia. En 1965, el director de Ayuda Militar, general Robert J. Wood, anuncia que «la principal finalidad del programa propuesto para el año fiscal 1965 en lo referente a ayuda militar a América Latina consiste en eliminar la amenaza que se cierne sobre la totalidad de dicha zona proporcionando equipo y adiestra-

6. Eil nuevo secretario de Estado del presidente Carter, Cyrus Vance, fue uno de los subsecretarios de defensa de Ia época de Mac Namara, es decir, del período en que el Pentágono fue reestructuradio. 
miento que refuerce la capacidad de mantenimiento de la seguridad interna en los países beneficiarios». ${ }^{7}$ En 1967, Mac Namara declara que «el principal objetivo del Pentágono en Amética Latina consiste en contribuir, siempre que sea necesario, al continuado desartollo de las fuerzas militates y paramilitares indigenas, con el frn de conseguir, en conjunción con las actuaciones de las fuerzas policiales y de Seguridad, el necesario orden domésticon. ${ }^{8}$

En el plano político civil se crea la Alianza para el Progreso destinada a apoyar algunos cambios estructurales latinoamericanos, como la reforma agraria y la reforma presupuestaria, pero cuyas actividades decaen rápidamente sin haber logrado casi ninguno de sus objetivos. Es así como surge la tesis de que los ejétcitos latinoamericanos deben prepararse para intervenir en $\mathrm{Ia}$ vida política de sus países. Existe, por lo demás, una tradición histórica de militarismo latinoamericano y de participación de sus hombres en el poder político. Esta tradición es recogida por los Estados Unidos, quien entrena ahora a los oficiales latinoamericanos para convertirlos en aliados de sus propios intereses una vez que éstos asumen el gobietno, esta vez con una perspectiva de largo plazo. El apoyo financiero (armas y equipo) se complementa con la creación de una nueva ideología político-militar. Mac Namara, en una declaración ante una comisión de la Cámara de Representantes de los Estados Unidos, señalaba: «Es probable que Ios mayores beneficios de nuestra inversión en ayuda militar procedan de la tarea de adiestramiento de oficiales previamente seleccionados y de especialistas clave, en nuestras escuelas y centros de enseñanza, tanto en los Estados Unidos como en uitramar. Cuando estos alumnos regresan a sus países de origen, se destinan a la función de instructores. Son los futuros dirigentes, los hombres que conocen la técnica y que la enseñan a sus fuerzas. No creo necesario subrayar el valor de tener, en aitos cargos directivos, en sus países, a hombres que poseen un conocimiento directo de cỏmo los norteamericanos hacen las cosas y de cómo piensan. Reviste para nosotros un valor inapreciable que tales hombres sean amigos nuestros.» ${ }^{9}$

Entre 1950 y 1969 , el Departamento de Defensa adiestra a 50.181 of-

7. General Robert J. Wood, «Addres before the Los Angeles World Affairs Council» ( 3 de diciembre de 1964), citado en Klate, La guerra..., op. cit., p. 242.

8. Foreing Assistance, 1967, p. 540; citado en Klare, La guerra.., op. cit., p. 242.

9. U. S. House of Representatives, Committee on $\Lambda$ ppropriations, Subcommittee, Foreing Operations Appropriations for 1963, Hearings 87tb Congress, 2nd Session (Washington D.C.: U. S. Government Printing Office, 1962), p. 359. Citado en Klare, La guerra..., op. cit., p. 256. 
ciales y suboficiales latinoamericanos, 22.059 de elios entre 1964 y $1968 .^{10}$ La mayoría de los militares que hoy ocupan cargos de gobierno en los países regidos por dictaduras militares han pasado por estos cursos. Los ejéŕcitos latinoameticanos se convierten así no en los defensores de sus países contra cualquier agresión externa (tatea que asumitá Estados Unidos directamente de acuerdo con el tratado de Río de Janeiro), sino en los "mantenedores del orden público», de la «seguridad interna» y en el único «partido político» que puede gobernar y desarrollar económicamente sus países. El Brasil es el primer país en poner en práctica esta doctrina cuando la movilización popular se hace insostenible, convirtiéndose en precursor de lo que sucederá más tarde en otros lugares.

Es poco probable que en un futuro cetcano se vuelvan a restablecer regímenes verdaderamente democráticos o que logren acceso al poder, sólo por medios políticos, grupos civiles que propugnen programas de transfor maciones profundas tendentes a terminar con la dependencia. La experiencia chilena parece definitiva. Es, pues, en este contexto que se debe analizar el desarrollo de la lucha armada en América Latina como un fenómeno político.

\section{Sobre el extremismo}

La primera cuestión a considerar es si el fenómeno de lucha armada en América Latina y el accionar de los grupos guerrilleros es un fenómeno de extremismo político. Como se señaló, el extremismo político es una manifestación política marginal en una sociedad. Se caracteriza por proponer «medidas extremas» en circunstancias en que no se requieren. Un ejemplo es el uso de la violencia política cuando existen otros mecanismos alternativos y válidos de participación política que permiten el acceso al poder. Muchas veces es difícil distinguir entre extremismo político e iniciación de nuevas formas de lucha. Pero, el extremismo político se caracteriza por su incapacidad de generar un movimiento de apoyo político de proporciones considerables.

Se dijo que se distinguirían las distintas formas de violencia política, según tres indicadores generales: la situación en que ésta aparece (legitima o ilegítima); la relación con la población (apoyo o falta de apoyo), y las formas de expresión (discriminada o indiscriminada).

La descripción que se ha hecho sobre la situación latinoamericana

10. Klare, La guerra..., op. cit., Apéndice E. 
muestra cómo la mayoría de las formas de participación política han sido eliminadas o fuertemente restringidas. Esto implica que los grupos que se proponen terminar con la situación de dependencia necesariamente deben buscar formas alternativas de liegar ai poder. Es así como se puede afirmar que la situación misma de América Latina es potencialmente fuente de violencia política, en la medida en que se mantiene un statu quo neocolo nial también por medios violentos (contrainsurgencia).

De hecho, la violencia política ha ido en constante aumento en los últimos años, del mismo modo que la lucha armada como medio para obtener la independencia ha ganado un número cada vez más creciente de militantes y simpatizantes. Si bien los grupos guerrilleros han sido reprimidos con mucha fuerza, logrando su aniquilamiento en muchos casos, si se observa América Latina en conjunto se puede afirmar que el fenómeno de la lucha armada no ha sido totaimente controlado, sino que, por el contrario, se puede hablar de un salto cualitativo desde los primetos focos guerrilleros hasta, por ejemplo, las fuerzas de los Tupamaros uruguayos, el ERP o los Montoneros argentinos. Este salto cualitativo se ha manifestado en el crecimiento de los grupos guerrilleros, en el creciente apoyo (o, por lo menos, simpatía) por parte de ciertos grupos políticos tradicionales y en la expansión de la guerrilla a prácticamente todos los países latinoamericanos.

Luego de la victoria de la revolución cubana aparecen los primeros focos guerrilleros en Centro América y Venezuela. Su objetivo político general era la toma del poder para seguir el ejemplo cubano, es decir, una revolución antiimperialista y socialista. Las metas socialistas están estrechamente ligadas a la necesidad de romper con los lazos de Ia dependencia. Su medio para lograrlo es el establecimiento de grupos guerrilleros rurales, que constituirán un movimiento de liberación que ha de llegar al gobienno. En Venezuela están próximos a logrario, contando con el apoyo de la izquierda tradicional (Partido Comunista Venezolano). Estos primeros intentos terminan con el fracaso y el casi aniquilamiento de estos primeros focos. También termina en el fracaso el intento del Che en Bolivia, que tiene por objetivo dar un nuevo impulso a la lucha armada. Esta derrota parece marcar el fin de la guerrilla. Sin embargo, en Brasil, Uruguay y Argentina, países tradicionalmente considerados como «no violentos», surge la guerrilla urbana. En Uruguay y Argentina realizan operaciones militares de gran envergadura, lo que supone organizaciones con un gran nivel de militantes, recursos y apoyo logístico. Al mismo tiempo, en países en que los grupos guerrilleros parecían totalmente extinguidos (Colombia y Nicaragua, por ejemplo) aparecen sucesores de los desaparecidos o nuevas organizaciones. Es decir, los constantes fracasos no parecen engendrar la desa- 
parición de la guerrilla, pues ésta reaparece bajo otras formas y en otros lugares, y cada vez con una capacidad operativa superior. Por ello, se puede afirmar que, tomando a América Latina en forma global, ha habido un crecimiento de los grupos guerrilletos.

En su aspecto político, la tendencia de la guerrilta ha sido la de intentar la formación de amplios frentes políticos. Es difícil evaluar (dada la situación de represión) la magnitud que ha logrado este intento. Sin embargo, resultados electorales como el del Frente Amplio del Uruguay, por ejemplo, parecen señalar que el número de simpatizantes de la lucha armada ha ido en constante aumento. Grupos políticos tradicionales, también, incorporan a la guertilla como forma de lucha (el caso del peronismo, por ejemplo) o prestan indirectamente su apoyo. Al mismo tiempo, el ejército, entrenado ideológicamente para considerar a los guerrilleros como sus principales enemigos, muestra algunos quiebros: Torres en Bolivia, Torrijos en Panamá, el intento peruano o la incorporación de algunos oficiales a los grupos guerrilleros. La lucha armada se convierte así en una forma de lucha con presencia en el escenario político latinoamericano.

En suma, tanto desde el punto de vista de la situación latinoamericana como del apoyo logrado por quienes patrocinan la lucha armada, no parece que se trate de un fenómeno de extremismo político. La violencia política en América Latina no sexía un asunto marginal que tiende a desaparecer, sino, por el contrario, un mecanismo politico que ha ido en aumento.

Cabe, entonces, analizar las posibilidades que tiene de alcanzar el poder o el tipo de objetivos políticos que podrá lograr. Al mismo tiempo, la dureza de la represión en los últimos tiempos plantea el problema de la supervivencia tanto física como política de los grupos guerrilleros más conocidos. Esto lleva al análisis de las formas que ha tomado la lucha armada y cuáles son sus perspectivas futuras.

\section{Sobre el terrorismo}

Otra afimación superficial sobre la guertilla latinoamericana es la de que ésta ha sido terrorista. Se hace referencia, en este caso, al tercer indicador general señalado, es decir, las formas de expresión de la violencia.

El terrorismo es la forma extrema de la violencia política. Si bien su análisis es un tema complejo, a modo general se podría afirmat que su característica principal es el uso de la violencia con escasa discriminación de los individuos o bienes contra los que se dirige. Tiene un componente político (si no estaríamos en el campo de la criminalidad) en el sentido de que la violencia se usa para aicanzar el podet. En su acepción más extre- 
ma, casi se podría afirmar que su trasfondo es la legitimación de la violencia por sí misma. Suele ir acompañada por una valoración positiva de los efectos liberadores, a nivel psicológico, de su uso.

En general, los grupos terrotistas suelen ser grupos pequeños, muy cerrados, que no se plantean la necesidad de construir amplios movimientos políticos. En este sentido, el impacto que sus operativos causan en la opinión pública de los grupos a los que se pretende representat, no es un elemento a tomat en cuenta en la planificación de las acciones. Del mismo modo, éstas no se enmarcan dentro de objetivos políticos precisos (más allá de la mera destrucción del poder establecido).

Estas características se refieren al terrorismo como un fenómeno puro. Sin embargo, hay otro tipo de terrorismo que es el que surge como una desviación de la lucha armada en determinadas situaciones o como un subproducto de la misma. Desviación: en el sentido de que ciertas acciones dentro de la lucha armada (sobre todo si ésta es prolongada) pueden convertirse en terroristas. Subproducto; cuando grupos guerrilletos se desprenden de su organización revolucionaria o logran sobrevivir al exterminio de ella en condiciones muy hostiles y se dedican al pillaje.

En el Tercer Mundo, en general, el terrorismo ha aparecido con mayor intensidad y frecuencia en las luchas de origen religioso o racial, en las que lo politico se combina con una o las dos variables (Irlanda o la lucha palestina, por ejemplo). En las revoluciones socialistas, en cambio, si bien no ha estado ausente, ha tenido un carácter matcadamente marginal. ${ }^{11}$

En la guerrilla latinoamericana el terrotismo ha sido excepcional y, casi siempre, un subproducto de la lucha. El carácter mismo de la lucha guerrillera, hasta hace poco foquista y campesina, es su mejor comprobación (si se quiere hacer terrorismo no se tiende a ir a zonas con poca población en las cuales formar un ejército). En el caso de la guerrilla urbana ha habido más atentados contra personas individuales que en la guerrilla rural, caracterizada por combates de tipo militar con tropas regulares. Sin embargo, estos atentados han estado casi siempre dirigidos contra personas ditectamente ligadas a los aparatos de represión y de lucha antiguertillera. En cuanto a los atentados contra bienes materiales, éstos han estado destinados, sin excepción, a destruir o dañar propiedades extranjeras pertenecientes a las corporaciones multinacionales. Además, estos atentados no son el único tipo de operaciones que se realizan, sino que forman parte de un contexto de acciones militares (enfrentamientos con tropas regulares, asaltos a unidades militares) más amplias. ${ }^{12}$

11. Los escritos de Frantz Fanon son ilustrativos de ese fenómeno.

12. Como ya señalamos, la prensa suele contar sólo la parte de la historia. Es así 
La lucha armada en oposición al terrorismo se ha caracterizado no solamente por el desarrollo de acciones militares, sino porque éstas han estado encuadradas dentro de un contexto político que busca la cteación de un movimiento popular que la apoye y sea su base de sustentación. Vale decir, por la existencia de grupos político-militares en los cuales lo militar está subordinado a lo político. Si bien es cierto que en algunas experiencias revolucionarias ha aparecido en ocasiones un predominio de lo militar, esto ha sido considerado siempre como una «desviación militarista».

\section{Sobre el foquismo}

La lucha armada ha adoptado diversas formas y manifestaciones: insurgencias, guerras campesinas, guerras populares, insurrecciones armadas, focos. Como es un proyecto político-militar, su accionar debe partir de un análisis de qué hacer, cómo hacerlo y con quién. Qué hacer significa el establecimiento de las metas políticas que se deben lograr en cada una de las etapas (el objetivo final es alcanzar el poder). Cómo hacerlo se refiere a la combinación de las diversas formas de lucha politica y militar que deben primat en cada circunstancia según las metas establecidas y las condiciones de la realidad. Con quién es el análisis de quiénes son los enemigos y quiénes los aliados y cómo lograr que se establezca este límite entre ambos.

Es la respuesta a estas tres preguntas en cada circunstancia histórica concreta, lo que ha conducido a las distintas expresiones de la lucha armada. Es la respuesta acertada al proceso en su conjunto (siempre hay errores más o menos transitorios) lo que da nacimiento a una revolución victoriosa. $\mathrm{Y}$ son estas últimas, como siempte suele suceder, las que han sido más estudiadas y las que han tendido a convertirse en modelo de los procesos revolucionarios que comienzan. Lo que tienen en común es que ninguna situación se ha reproducido en forma idéntica, pero, en todas, la clave del éxito parece haber sido una correcta relación entre los grupos de vanguardia que encabezan la lucha y la parte de la población que la apoya y sostiene. El lograr que los objetivos de la revolución sean compartidos por la mayor cantidad posible de sus fututos destinatarios y que se establezca una organización que pueda superat los crecientes problemas y sobrevivir, parece

como siempre se destaca el número de muertos o las bombas, pero sin decir contra quiénes iban ditigidas o las actividades de las personas muertas. Esto forma parte de la censura impuesta por casi todos los gobiernos latinoamericanos. 
ser el elemento común trás importante. Aparte de esas connotaciones semejantes, las predicciones acertadas parecen haber sido escasas y las sorpresas muchas.

En América Latina el modelo del cual partieron los primeros grupos guerrilletos fue la revolución cubana. Dos elementos de ella fueron considerados los más importantes: la guerrilla rural y el establecimiento de focos político-militares en las regiones en que la naturaleza lo permitiera. Estos focos iniciarían la lucha e irían incorporando a distintos sectores de la población. Su eje central sería la lucha antiimperialista combinada con objetivos socialistas. Como en Cuba el proceso revolucionario desde el establecimiento del foco hasta la toma del poder había sido corto, se esperaba que también lo sería en los países en que se formaran los primeros focos guerrilleros.

Esta concepción se conoce como la expresión foquista de la lucha armada. Caracterizó el nacimiento y desarrollo de grupos guerrilleros du* rante la década de los sesenta en diversos países latinoamericanos. Si bien aparecieron focos guerrilleros en varios lugares y en Venezuela y Guatemala tuvieron un impacto importante en las estructuras del poder, el balance de la década fue negativo en términos de los objetivos planteados. Políticamente los grupos no lograron crecer significativamente. Militarmente, la mayoría de ellos fueron derrotados o, por lo menos, dispersados y reducidos a operar en zonas limitadas. Así, la concepción foquista hizo crisis. Su sistematizador intelectual, Régis Debray (¿Revolución en la Revolución?), afirma hoy: "¿En qué consistía finalmente el defecto de ¿Revolución en la Revolución? En que el razonamiento presentado hacía economía de las premisas (político-económicas) para llegar inmediatamente a las conclusiones; presentaba un resultado (la guerrilla en acción, vinculada al pueblo y transformándose en vanguardia política de la nación) privado de sú génesis, cierto producto militar sin sus condiciones de producción (económicas, sociales y políticas). Se prescindía de los objetivos previos de la guerra de guerrillas para fijarse en los métodos adectuados para asegurar su éxito militar, una vez puesta en marcba la guerrilla. En otros términos, este texto daba indicaciones útiles, en abstracto, sobre la manera de resolver el problema del poder, sin ocuparse de saber si las condiciones objetivas estaban reunidas para resolverlo bic et nunc. Por eso to subjetivo se desprendía de to objetivo; las reglas de la acción revolucionaria, consciente y organizada, de las leyes de lucha de clases y de su desarrollo; el arte militar, de la "ciencia" política. Las premisas de una guerra victoriosa no estaban más presentes en la realidad política de entonces que en sus reflejos ideológicos. Y, con razón: el estado real de la relación de fuerzas en América Latina 
en aqueila época, no era nada favorable, objetivamente, para una ofensiva revolucionaria.. ${ }^{13}$

Sin embargo, el accionar de la guertilla tuvo consecuencias políticas en el continente. Es merced a este fenómeno, entre otros, que al iniciarse la década de los setenta se presencia un renacer de la movilización política antiimperialista en América Latina. Hay gobiernos que se definen como antiimperialistas en Perú, Panamá, Bolivia, Chile y Argentina. En otros países los grupos revolucionarios logran importantes avances electorales. En todas partes hay un renacer de sentimientos nacionalistas que exigen, por lo menos, un mayor distanciamiento del podet central. En tétrinos de concepción política, la experiencia foquista de la década de los sesenta abrió el camino a la conciencia sobre la dependencia y sus implicancias. Es decir, plantea la necesidad de realizar la revolución latinoamericana con un marcado carácter antiimperialista.

\section{Hacia la guerra popular}

Guerra popular (o guerra de liberación) es el término general que se ha usado para caracterizar las luchas de liberación de los países coloniales y neocoloniales de Africa y Asia. En ellas lia lucha por la independencia ha ido acompañada por objetivos socialistas. Vietnam es el ejemplo más ilustrativo. Sus características principales han sido: larga duración en el tiempo, son guerras prolongadas; han abarcado prácticamente toda la extensión territorial y toda la población de dichos países; han logrado movilizar en su apoyo vastos sectores de la población, incorporando a casi todos los grupos sociales, precisamente por su carácter nacionalista; los objetivos de liberación nacional han ido acompañados de metas socialistas: no sólo buscan la independencia, sino la construcción de un régimen socialista, cuyo principal apoyo sean los trabajadotes, eje de la alianza de los distintos grupos sociales.

Las tesis centrales de la guerra popular han servido como guía a diversos movimientos de liberación nacional, muchos de los cuales obtuvieron la victoria y llegaron al poder (China, Vietnam, Laos, Corea y varios países africanos, Angola el más reciente). La aplicación de estos principios ha variado en cada ocasión concreta, pero dos características de las formaciones sociales en que se han producido son comunes: son países coloniales o con un agresor externo claramente identificado; y son países rurales.

13. Régis Debray, La Critica de las Armas (Madrid: Siglo XXI, 1975), pp. 217-218. 
Estas dos características han posibilitado dos fenómenos importantes: la creación de amplios frentes políticos basados en los sentimientos nacionalistas de la población y la creación de ejércitos populares, con un asentamiento geográfico en el cual establecerse y desde el cual operar. Apoyados en estos dos factores es como los movimientos de liberación nacional han podido llegat al poder. Las derrotas sufridas en el transcurso de la lucha no los aniquilaron, pues siempre había sectores de la población dispuestos a reemplazar a los caídos (por su amplia base social), y «zonas liberadas» donde organizarse nuevamente. Ambos hechos, en general, les permitió hacerle frente a una lucha prolongada en la que el poder colonial siempre se desgastó en mayor medida. (Es por ello, precisamente, que uno de los principios fundamentales de la contrainsurgencia es terminar con los grupos independentistas muy al comienzo de la lucha y lo que explica, en parte, la dureza de la represión en América Latina.)

El fracaso de la mayoría de los focos rurales en América Latina los impulsó a una completa tevisión de sus objetivos y de sus formas de lucha. Las conclusiones de casi todos ellos fue que la guerrilla debía organizarse en torno a los principios centrales de la guerra popular como forma de Iucha. Con ello se proponía, fundamentalmente, el que los guerrilleros no debían constituirse en focos aislados, sino que debían construir una base política que les sirviera de sustentación y que era tan importante como la capacidad militar. El trabajo político debía ser simultáneo con el operar militar. Es decir, los grupos antiimperialistas deberian construir un amplio movimiento de liberación en el que el foco guerrillero fuera su brazo armado. Estos nuevos objetivos respondían, también, a una nueva evaluación de la situación política continental: por un lado, reflejaban el intento de incorporar a la lucha armada a los grupos políticos antiimperialistas cuya movilización había precedido a los golpes militares (sobre todo en el cono sur); por otro lado, respondían a la constatación de que, debido a la rápida respuesta por parte de las fuexzas represivas, la lucha no tendría la corta duración que se había pensado, sino que tendría todas las características de lo que se denomina «guerra prolongada». Es en estos términos que los grupos guerrilleros han realizado sus acciones más tecientes (por ejemplo, en Argentina, donde ha habido mayor actividad guerrillera).

Esta nueva visión de los objetivos de la lucha armada parece ser, por parte de los grupos guerrilleros, la reafirmación del carácter neocolonial de América Latina. Cabría preguntarse, sin embargo, si no hay diferencias importantes entre los países que dieron origen a las guerras populares y los latinoamericanos.

Hablar de América Latina como un todo es correcto sólo en parte. Si bien hay problemas y características comunes, también hay diferencias 
entre los paises centro americanos, por ejemplo, y los países del cono sur. Teniendo en cuenta estas diferencias, aun así las formaciones sociales de estos países difieren de las de los países coloniales por lo menos en dos aspectos: no hay un agresor externo independiente de grupos nacionales (esto es, precisamente, lo que hemos llamado neocolonialismo), y no hay zonas geográficas que puedan servir de «zonas liberadas» (con apoyo de la población) o países vecinos que sirvan de apoyo (excepto Cuba, y, ésta es una isla). La primera diferencia apunta a las diffcultades para construir un "frente de liberación nacional», con componentes de todas las clases sociales. La segunda indica los problemas que existen para constituir un ejército de liberación con un lugar en el cual establecerse que sirva de base de operaciones. La guerra popular, si se desarrolla, tiene más bien la connotación de que deberá ser una «guerra civil popular», dado que el imperialismo se caracteriza, en este caso, por actuar a través de sus aliados locales. Es decir, las características estructurales mismas de América Latina dificultan el desarrollo de una guerra popular, por lo menos, con las formas que ha tomado históricamente en los países donde ha resultado victoriosa.

Tenemos así que las características mismas del neocolonialismo impiden tanto el desarrollo de formas de lucha atmada, como el desarroilo de la lucha por la independencia a través de los mecanismos políticos tradicionales. Es imposible pensar en romper la dependencia sin tecurrir de algún modo a la violencia política (porque como se señaló, el imperialismo está dispuesto a impedirlo también por las armas), pero es difícil el desartollo de una organización política amplia en la cual enmarcarla. En esta situación es difícil predecir cuál será el futuro de la guerrilla. Sin embargo, se podrían aventurar algunas hipótesis.

En primer lugar, que el fenómeno de la violencia política no parece que desaparecerá en el corto plazo, sino que tenderá a crecer. Ya sea a través de las organizaciones guerrilleras que hoy existen, o con el surgimiento de nuevas organizaciones. En segundo lugar, que es probable que este proceso sea de larga duración. En este sentido la lucha que se desarrolle sí es probable que se asemeje a una guerra popular. En tercer lugar, que las dificultades para la creación de un ejército popular se traducirán, más bien, en operaciones militares en las que las formas de guerrilla urbana tengan un papel creciente. Esto, evidentemente, dependerá del país de que se trate. En el caso del cono sur, y más especificamente de Argentina, ésta ha sido la tendencia que se ha consolidado. En otros países más rurales es posible que haya una forma combinada de lucha. En todo caso, no parece probable que se consoliden «zonas liberadas», de modo que la base de operaciones de los guerrilleros tenderán a ser móviles: es decir, es pro- 
bable que las acciones militares de la guerrilla se realicen alternadamente en distintos lugares geográficos. Finalmente, parece que, al menos en el corto y mediano plazo, la lưcha armada está más bien en situación de abrit espacios políticos que de conquistar el poder. Con esto se quiete decir que los grupos políticos tradicionales tienen mayor capacidad de negociación con el poder establecido gracias a, precisamente, la existencia de focos de lucha armada. Esto quizás llevará a un replanteo de las relaciones entre los grupos políticos tradicionales y las organizaciones guerritleras.

\section{Conclusiones}

Se ha intentado demostrar en este trabajo que las manifestaciones de violencia política en América Latina no son expresiones de terrorismo o de extremismo político, sino que son una forma embrionaria de lucha armada en una situación que bloquea las posibilidades de cambio social a través de los mecanismos meramente políticos. En este sentido, a pesar de más de cien años de independencia política, los países latinoamericanos se asemejan más a los países africanos y asiáticos que a los países europeos. Es por esto que el uso de categorías políticas adecuadas para la descripción de los fenómenos de violencia en Eutopa no lo es para entender a la guerrilla latinoamericana. Si bien no es posible predecir aún cuál será el resultado en el largo plazo de esta lucha atmada, tampoco es ya posible ignorar su existencia o reducirla a un problema marginal y disfuncional como puede ser el terrorismo.

Si se les permitiera a los pueblos latinoamericanos ser dueños de sus propios recursos para que éstos sirvieran para lograr su propio desarrolio económico y social (en lugar de contribuir al de los países capitalistas centrales), también éstos estarían hoy en situación de poder intentar conseguir sus «vías pacíficas hacia el socialismo». Pero, como no es éste el caso, por duro que sea, la violencia política seguirá creciendo, transformada en un mecanismo político legítimo (en el sentido sociológico).

\section{JUDITH LARSON}

